\title{
SACRECTOMY ASSOCIATED WITH VERTEBRECTOMY: A NEW TECHNIQUE USING DOWEL GRAFTS FROM CADAVERS
}

\section{SACRECTOMIA ASSOCIADA À VERTEBRECTOMIA: UMA NOVA TÉCNICA COM USO DE ENXERTO DE CADÁVER}

\author{
Thiego Pedro Freitas Araújo ${ }^{1}$, Douglas Kenji Narazaki ${ }^{2}$, William Gemio Jacobsen Teixeira ${ }^{2}$, Fábio Busnardo ${ }^{3}$, \\ alexandre Fogaça Cristante ${ }^{4}$, Tarcisio Eloy Pessoa de Barros Filho ${ }^{4}$
}

1. Institute of Orthopedics and Traumatology, Hospital das Clínicas da Faculdade de Medicina da Universidade de São Paulo (IOT-HCFMUSP), São Paulo, SP, Brazil. 2. Spine Surgery Division, Tumors of the Vertebral Spine, Hospital das Clínicas da Faculdade de Medicina da Universidade de São Paulo (IOT-HCFMUSP), São Paulo, SP, Brazil. 3. Surgery Division, Faculdade de Medicina da Universidade de São Paulo, São Paulo, SP, Brazil.

4. Medical Investigations Laboratory, Spine Surgery Division, Hospital das Clínicas da Faculdade de Medicina da Universidade de São Paulo (IOT-HCFMUSP), São Paulo, SP, Brazil.

\section{ABSTRACT}

Objective: The purpose of this study was to demonstrate, in a case series, a new sacrectomy technique using an iliac crest dowel graft from a cadaver. Study design: Report of a case series with description of a new surgical technique. Methods: The technique uses four bars to support the posterior spine and a dowel graft in the iliac wings, with compression of the spine and pelvis above it, to support the anterior spine. Three cases were operated on, and in all of them, a vertebrectomy was used. Results: In the first two cases, the technique was performed as a two-stage surgery. The first stage was performed via the anterior and peritoneal access routes, and the second stage via the posterior access route. In the third case, retroperitoneal access via the anterior route meant that the technique could be performed in one stage, resulting in an overall reduction in surgical time (1250 vs. 1750 vs. 990 minutes, respectively). Conclusion: The new technique enables fixation with biomechanical stability, which is essential to support the stress in the lumbosacral transition and promote earlier rehabilitation. Level of evidence IV, case series.

Keywords: Spine. Cadaver. Lumbosacral Region. Bone neoplasms.

\section{RESUMO}

Objetivo: O propósito do estudo foi demonstrar, por meio de uma série de casos, uma nova técnica de sacrectomia com uso de enxerto encavilhado da crista ilíaca de cadáver. Desenho do estudo: Relato de série de casos com descrição de uma nova técnica cirúrgica. Métodos: A técnica usa quatro barras para sustentação da parte posterior da coluna e um enxerto encavilhado nas asas do ilíaco, com compressão da coluna e pelve sobre ele, para suporte da parte anterior da coluna. Foram operados três casos e em todos eles, realizou-se vertebrectomia. Resultados: Nos dois primeiros casos, a técnica foi utilizada em duas etapas. A primeira etapa foi realizada por via anterior e acesso peritoneal, e a segunda etapa, por via posterior. No terceiro caso, o acesso retroperitoneal por via anterior significou que a técnica pôde ser realizada em apenas uma etapa, resultando em redução do tempo cirúrgico total (1250 x 1750 × 990 minutos, respectivamente). Conclusão: A nova técnica permite a fixação com estabilidade biomecânica, que é essencial para suportar a tensão na transição lombossacral e para a reabilitação precoce. Nível de evidência IV, série de casos.

Descritores: Coluna vertebral. Cadáver. Região lombossacral. Neoplasias ósseas.

Citation: Araújo TPF, Narazaki DK, Teixeira WGJ, Busnardo F, Cristante AF, Barros Filho TEP. Sacrectomy associated with vertebrectomy: a new technique using dowel grafts from cadavers. Acta Ortop Bras. [online]. 2018;26(4):260-4. Available from URL: http://www.scielo.br/aob.

\section{INTRODUCTION}

Primary tumors of the sacrum are uncommon, representing approximately $1 \%$ of all spinal tumors. ${ }^{1}$ They are located in an anatomical region that is unfavorable for resection, particularly in cases of total sacrectomy, due to their position in relation to the adjacent tissues and viscera. Sacrectomy usually involves a motor deficit, as well as sexual, seminal vesicle and rectal dysfunctions. ${ }^{2}$ En bloc resection with wide margins is the treatment of choice for primary tumors that do not respond to radiotherapy or chemotherapy, such as chordomas and chondrosarcomas. It is also indicated for aggressive benign tumors, such as giant cell tumors. ${ }^{3}$ When they affect the spine, these tumors most commonly occur in the sacrum in the third or fourth decade of life. ${ }^{4}$

There is currently no consensus as to the best reconstruction technique following sacrectomy due to the low frequency of cases and the variety of techniques that have been described., ${ }^{3,5-8}$ In addition, there are reports in the literature of cases where reconstructions were not performed but that still showed good long-term results. The problem is not the reconstruction itself but instead the rehabilitation as the patient must be restricted to the bed for a long period.

\section{All authors declare no potential conflict of interest related to this article.}

Work conducted at Department of Orthopaedics and Traumatology, Instituto de Ortopedia e Traumatologia, Hospital das Clínicas da Faculdade de Medicina da Universidade de São Paulo (IOT-HCFMUSP), São Paulo, Brazil.

Correspondence: Alexandre Fogaça Cristante. Rua Dr. Ovídio Pires de Matos, 333, São Paulo, SP, Brazil. 04018-001. aacristante@uol.com.br 
In the study by Guo and Yadav, the patient restarted rehabilitation 45 days after sacrectomy and only experienced significant pain relief while getting up or sitting down when using a lumbar-sacral corset. ${ }^{9}$ The defect created after the resection causes the pelvic ring to become detached from the spine, and several techniques have been described to address this issue: screw fixation of the sacroiliac joint, fixation with transiliac rods, Galveston rods, and even custom-made prostheses. , $^{, 7,10}$ Biomechanical studies using cadavers and computer models have attempted to determine which reconstructions are more stable and better avoid breakage of the material in the lumbar-pelvic junction or the loosening of the synthesis material. ${ }^{11-13}$ Regardless of the chosen technique, the purpose of the surgery is to reestablish the connections and the support that the sacrum lends to the pelvis and spine.

We operated on three patients with primary tumors using en bloc resections of vertebrae $L 4$ and $L 5$ and the sacrum. The cases included a giant cell tumor, a chordoma, and a sarcoma of the peripheral nerve sheath. The first two cases involved two-stage surgeries. In the third case, it was possible to perform a one-stage procedure. Based on these three case reports, this study describes a new surgical technique for spinal-pelvic reconstruction with bone grafting after complex resections of the sacrum along with lumbar vertebrae.

\section{MATERIALS AND METHODS}

The study was conducted with new surgical technique performed in three consecutive cases of sacrectomy associated with vertebrectomy in diseases that required this kind of treatment. This study was approved by Ethics Committee of the Department of Orthopaedics and Traumatology, Instituto de Ortopedia e Traumatologia, Hospital das Clínicas da Faculdade de Medicina da Universidade de São Paulo (IOT-HCFMUSP), number 1252, with written informed consent obtained from all patients.

\section{Description of the surgical technique}

The vascular surgery team obtained anterior access by making an incision from the xiphoid process to the pubic symphysis, opening the peritoneum, retracting the intestinal loops, and accessing the retroperitoneal space. The infrarenal abdominal aorta was dissected, with the ligation of the lumbar arteries of the respective vertebrae ( $L 4$ and L5) to be resected en bloc together with the sacrum. Next, the internal and external common iliac arteries were dissected and retracted (Figure 1). The left and right hypogastric arteries and the median sacral artery were ligated (Figure 2).

At this point, the spinal surgery team began the first stage of the procedure. A dissection was performed to expose the anterior spine, and discectomy of L3-L4 was performed proximally, releasing the psoas muscle bilaterally along the sides of vertebrae L4 and L5. In the anterior region of the sacrum and the tumor, lysis of the structures was performed, which included the sacral roots, along with the release of the mesorectum with the aid of a 30-degree optic. The tumor was dissected laterally, with a wide margin that extended as far as the iliac crest. Osteotomy of the iliac bones was then carried out, extending laterally to the sacroiliac joints, and leaving the joint together with the piece to be resected as an oncological safety margin (Figure 3). Bovine pericardium was placed between the vascular structures that were released (aorta, inferior vena cava, iliac arteries and iliac veins) and the spine. The wound was closed by planes, and closure was performed according to normal procedures.

In a second surgical procedure, performed via the posterior route, a median incision and dissection of the soft parts were performed via the median route, exposing the laminae and transverse processes of the vertebrae to be fixed. Next, pedicle screws were inserted bilaterally in vertebrae T11 to L3 and S2, using bilateral iliac screws (Figure 4). The tumor mass was identified and dissected, taking care to remove the tumor capsule as a whole. This was followed

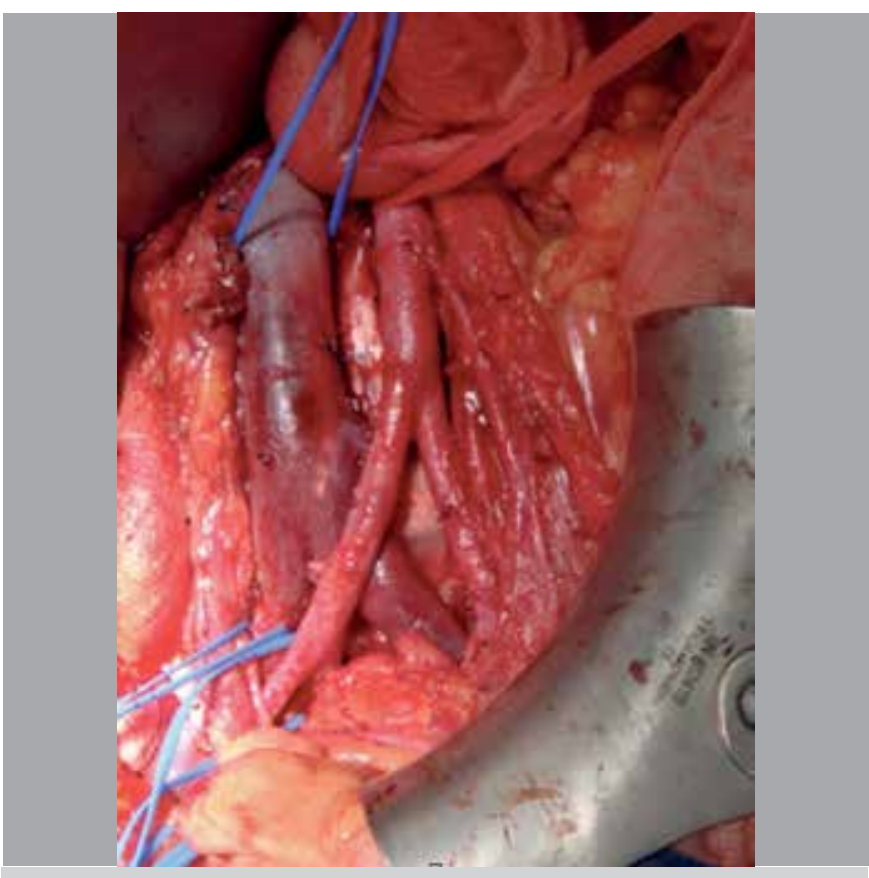

Figure 1. Surgery anterior access showing aorta artery, cava vein and iliac common artery and vein.

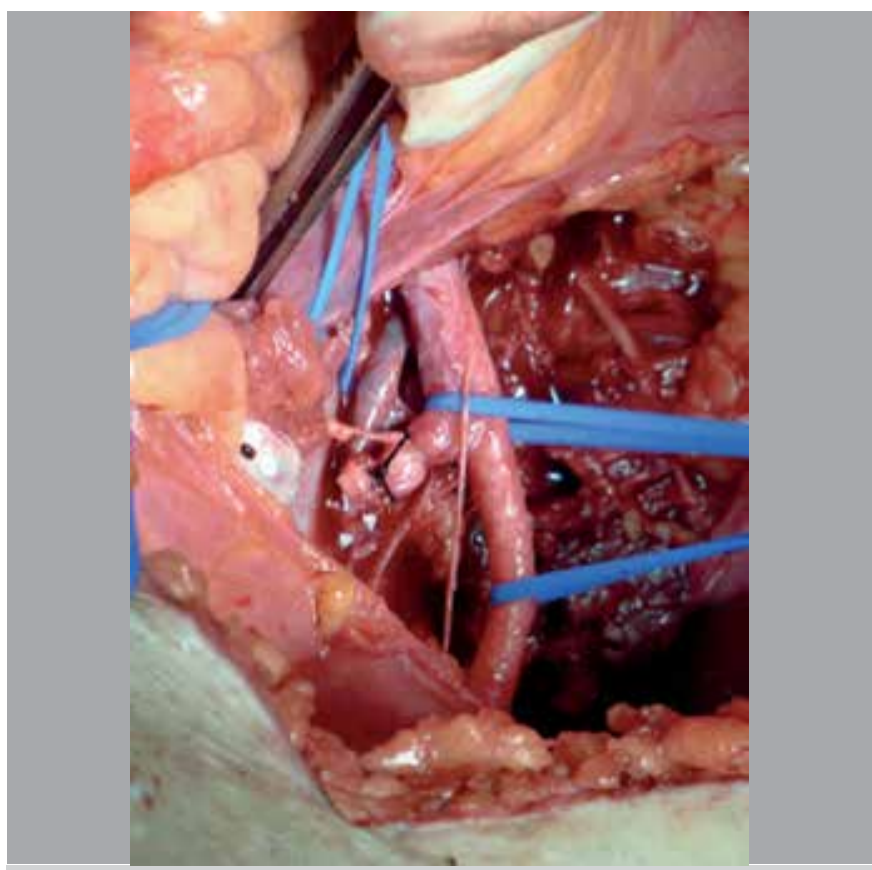

Figure 2. Ligated hypogastric artery.

by the laminectomy of $\mathrm{L} 3$ and the bilateral inferior facetectomy of L3. Next, ligation of the dural sac and roots was performed with 2.0 cotton thread, incising the roots of L4, L5, and S1-S5, and the suture at the bottom of the dural sac was reinforced with Prolene 4.0. Posterior L3-L4 discectomy was then performed. The musculature of the transverse processes and pedicles was released laterally. The osteotomy was complemented via the posterior route. Next, the posterior musculature of the sacrum was released, followed by a posterior proximal to distal rotation maneuver of the piece being removed ( $L 4, L 5$, sacrum) en bloc, followed by the lysis of previously mentioned structures under direct vision. 


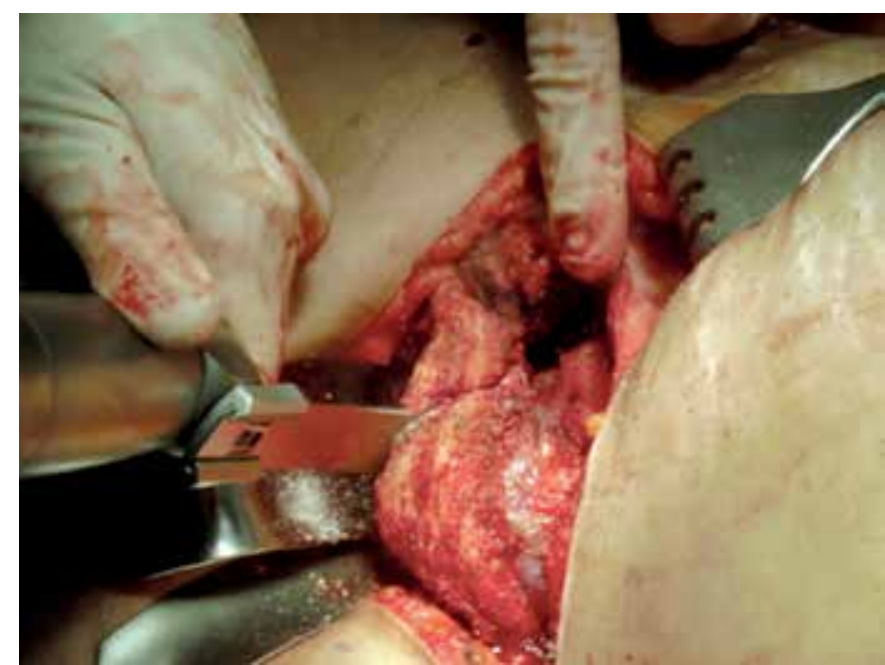

Figure 3. lliac wing osteotomy in anterior access.

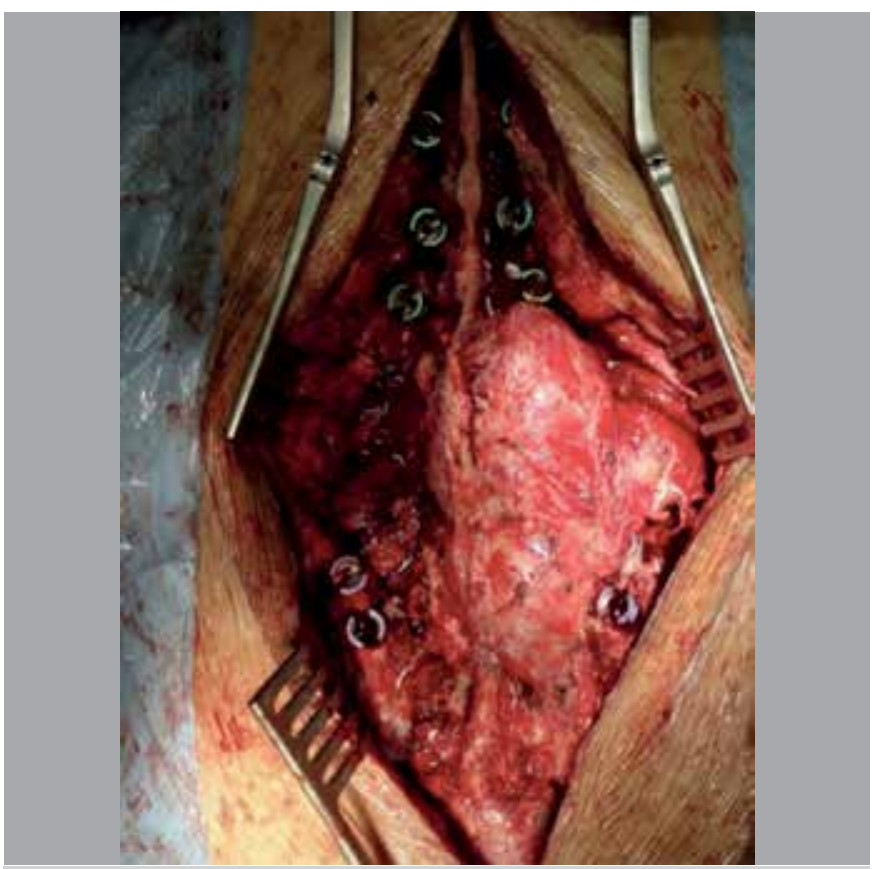

Figure 4. High-grade tumor of the peripheral nerve sheath in posterior view with pedicle and iliac screws.

The vertebrae (L4-L5) and the sacrum were removed en bloc with the tumor (Figure 5). A bone bank graft from the femur was inserted, and it was doweled into the two wings of the iliac after making a slit in the wings of the iliac crests, and the graft was positioned under pressure. Four bars were placed between the pedicle screws and the iliac screws. Compression between the spine and the graft was performed through the bars, placing a spongy bone graft in the areas of contact between the bone and the graft (Figure 6). At this stage of the surgery, plastic surgeons helped with replacing the soft tissue covering. The rotation of the rectus abdominal muscles or large dorsal muscles was used to reduce the dead space.

In the third patient operated on, the whole procedure was performed in just one surgical stage. The difference in technique was that it used a double retroperitoneal access to perform the surgical steps carried out via the previous route. This modification led to a significant reduction in surgery time. A bilateral and oblique incision was made in the hypogastric region, without opening the peritoneum, and the bowel loops were retracted to access the retroperitoneal space. The other steps were similar the steps of the procedures mentioned above. A summary of the data from the three cases is given in Table 1.

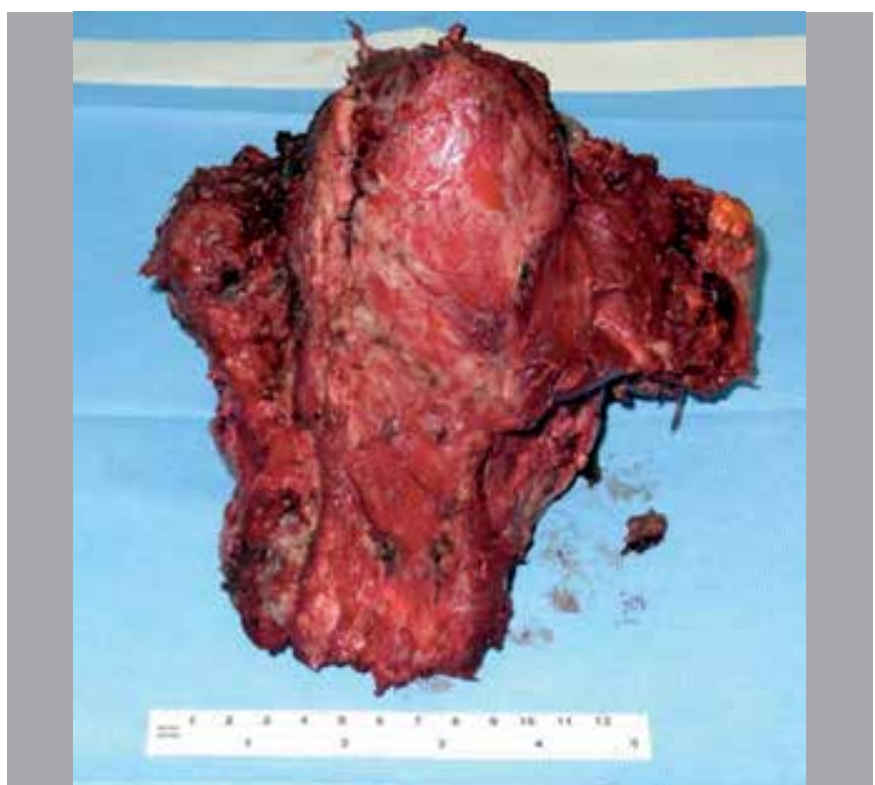

Figure 5. High-grade tumor of the peripheral nerve sheath en bloc resection.
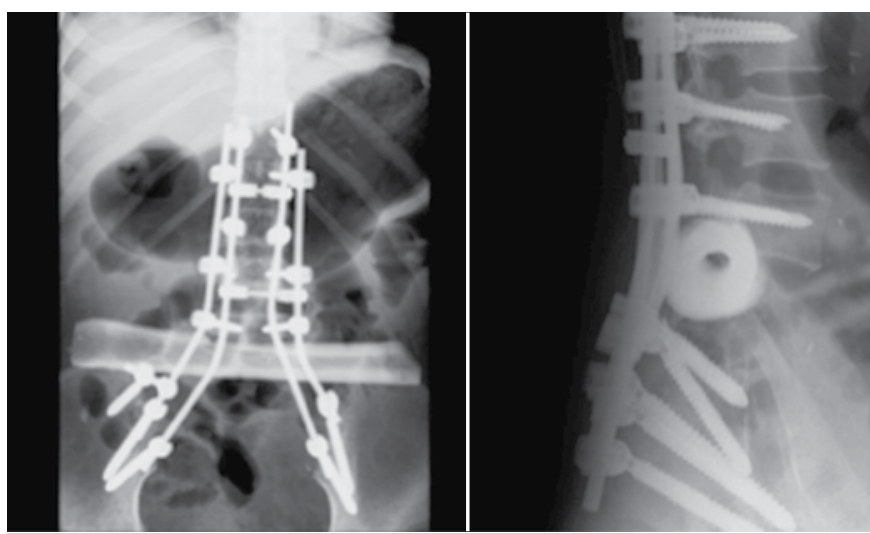

Figure 6. Postoperative radiographs showing compression of the graft with double bars fixation.

\begin{tabular}{|c|c|c|c|}
\hline & Case 1 & Case 2 & Case 3 \\
\hline Type of tumor & Chordoma & $\begin{array}{l}\text { Giant cell } \\
\text { tumor }\end{array}$ & $\begin{array}{l}\text { High-grade tumor of the } \\
\text { peripheral nerve sheath }\end{array}$ \\
\hline Surgical procedures & Two-stage & Two-stage & One stage \\
\hline First stage duration & $8 \mathrm{~h} 10$ & $10 \mathrm{~h} 30$ & $16 \mathrm{~h} 30$ \\
\hline Second stage duration & $12 \mathrm{~h} 40$ & $18 \mathrm{~h} 40$ & - \\
\hline Total time (min) & 1250 & 1750 & 990 \\
\hline $\begin{array}{l}\text { Erythrocyte concentrate } \\
\text { in the first stage (units) }\end{array}$ & 4 & 6 & 9 \\
\hline $\begin{array}{l}\text { Erythrocyte concentrate in } \\
\text { the second stage (units) }\end{array}$ & 10 & 12 & 0 \\
\hline
\end{tabular}




\section{Case Series}

We performed sacrectomy associated with vertebrectomy in three patients, who all presented with the long-term development of cauda equina syndrome.

The first two cases had positive margins in the resection, showing tumor recurrence. One of the three cases presented a loosening of the synthesis material. The patient with the chordoma had a recurrence three years and five months later in the allograft and in the quadrilateral laminae and was sent for treatment with radiosurgery. The recurrence of the giant cell tumor was treated with surgical resection en bloc. The first case had loosening of the iliac screws on the right side five months after surgery.

The osseointegration of the graft occurred at different points at different times. For example, integration in the second case occurred in one of the iliac bones at 12 months and in the other at 24 months. Computed tomography (CT) scanning was performed postoperatively at one year and five months and showed graft integration in the chordoma case (Figure 7). For more information on the follow-ups, see Table 2.

In rehabilitation, there was no restriction on immediately being in a standing position, but the plastic surgery team restricted it for three weeks on average to prevent the loss of the flap. During this period the patient was in a supine or lateral ventral position. After receiving the authorization of the plastic surgery team, the patient was allowed to walk according to the protocols of the physical therapy and physiatry teams.

\section{DISCUSSION}

Resection of the sacrum has a great impact on spinal-pelvic stability. In a study conducted on cadavers by Gunterberg et al., it was observed that sacrectomy at the level of S1-S2 resulted in a 30\% loss of strength in the pelvic ring, whereas the same procedure performed more cephalically, resecting $\mathrm{S} 1$ a centimeter below the promontory, increased this deficit to $50 \%$. However, the residual force was sufficient to allow early weight-bearing. ${ }^{14}$
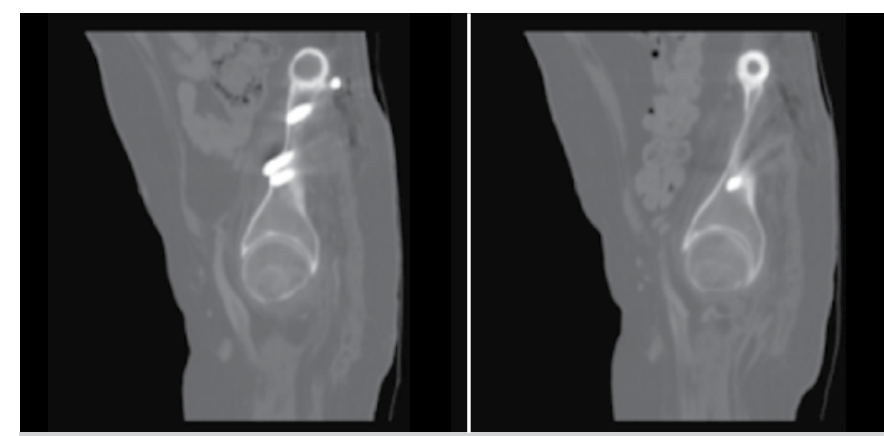

Figure 7. Computed tomography showing integration of allograft on both iliacs one year and five months after surgery.

Table 2. Follow-up data.

\begin{tabular}{c|c|c|c}
\hline & Case 1 & Case 2 & Case 3 \\
\hline Free margins & No & No & Yes \\
\hline Recurrence & 41 months & 8 months & No \\
\hline Osseointegration & 17 months $(\mathrm{I})$ & $12 / 24$ months $(\mathrm{I} / \mathrm{l})$ & $7 / 14$ months $(\mathrm{I} / \mathrm{S})$ \\
\hline Complications & Dehiscence & SIRS/ARI/UTI & SSI \\
\hline Walking? & Yes & No & Yes \\
\hline Adjuvant therapy? & No & zoledronic acid & radiotherapy \\
\hline Follow-up & 41 months & 46 months & 20 months
\end{tabular}

*3 points of osteointegration evaluated. I = iliac bone; $S$ = spine; SIRS = systemic inflammatory response syndrome; ARI = acute respiratory infection; urinary tract infection; SSI = surgical site infection.
Sacral tumors that are treatable via curative resection usually present with invasion of S1 and even of the lumbar vertebrae, causing the treatment to affect the stability of the spinal-pelvic junction. Subsequent reconstruction is therefore necessary. However, what the best reconstruction procedure has not yet been determined. In studies in cadavers and in computational analyses, it has been observed that constructions with double bars, with two iliac screws on either side of the iliac crest and with anterior support of the reconstruction, showed better biomechanical resistance, likely with greater safety and a faster rehabilitation. ${ }^{11,12}$ In the technique described in this case report, the reconstruction that gave anterior support to the spine was a dowel graft from the femur, which was supported both in the iliac wings and in the body of the lumbar vertebra.

In our cases, we started using a triangular reconstruction with a cadaver graft and fixation of the screws in the cadaver bone. In these cases, we found that the screws in the graft became loose. We then opted to alter the construction by not using synthesis material in the graft. This new technique presents biomechanical improvements relative to those previously used. It presents good load distribution on the reconstruction, as demonstrated by the biomechanical simulation of Kawahara et al., ${ }^{11}$ with good anterior and posterior support. In their biomechanical study, instead of a graft from the bone bank, the authors used a bar that connects the iliac wings to L5, resulting in a similar construction to the one used in our cases. No concentration of compressive load stress on the construction was observed, indicating the immediate rigidity and stability of the system, and resulting in earlier and safer rehabilitation. There is another reason for positioning the dowel graft in the iliac crests rather than in the sacral region. Our patients had involvement of the lumbar vertebrae, and en bloc resection in conjunction with the sacrum was necessary for treatment. Thus, the position of the graft results in a minimum loss of height, as it is positioned more cephalically than the original position of the sacrum.

Another factor to consider in the evolution of the technique is that it was performed in the third case via an anterior retroperitoneal access route, resulting in a significant reduction in surgery time, allowing a one-stage procedure. The total time was reduced by $21 \%$ in relation to the first case and by $43 \%$ in relation to the second. In addition to eliminating the need for a second procedure, this also saves hospital resources and makes the surgery more cost-effective. The spinal-pelvic junction experiences high levels of transmitted force, acting as a major lever arm in the lumbosacral junction. 5,15,16 To increase the stability of the construction and avoid screw pullout or breakage of the implants, other modifications were added to the technique. The use of four bars, as described by Shen et al., ${ }^{8}$ helps increase stability during flexion, extension and lateral flexion compared with the conventional use of two bars connected by a cross-link. In addition, a cross-link was used to increase the rotational resistance of the construction. ${ }^{17}$

Biomechanical studies in cadavers have demonstrated that the use of two iliac screws on either side offers adequate stability for compression and torsion, particularly when placed parallel to each other and angled towards the anterior-inferior iliac. ${ }^{18,19}$ This technique therefore involved the fixation of two iliac screws on each side. The use of a bone bank graft poses some risks, such as the high rate of non-integration with the living bone, the increased risk of infection, and the risk of disease transmission. We observed that all of our patients had some episode of infection, although without serious repercussions. In relation to the high rate of non-integration of the graft from the bone bank with the recipient's bone, another advantage of our technique is that when we create slits in the iliac bone and when performing compression of the spine over the iliacs, our technique favors the stability of the construction and the integration of the graft. ${ }^{20}$ 
Another development that we are currently working on relates to the anterior access route, with less morbidity and with double retroperitoneal access for the dissection of large vessels, discectomies, osteotomies of iliac bones lateral to the sacrum, and the release of the mesorectum anterior to the sacrum. We tend to avoid the ligation of the hypogastric arteries; therefore, we extended the option of coverage with the gluteal flaps, which would otherwise have been impaired as a result of ischemia. In addition, by not opening the peritoneum, it is possible to decrease surgical morbidity and postoperative complications such as paralytic ileus. In the last case of our series, the patient was operated on in just one stage, with less morbidity and a shorter overall surgery time.

\section{CONCLUSION}

We describe a new technique for spinal-pelvic reconstruction in patients who present potentially curable diseases of the sacrum that have extended to the lumbar vertebrae. Our technique has several biomechanical advantages; it avoids the use of synthesis material in the graft from the bone bank, and it places compression on the points of contact between the donor-recipient bone, favoring the integration of the graft. There is increased security in the fixation, and the construction quality is maintained over time. The technique also has the disadvantage that it uses a bone bank graft. Further studies are needed, with longer follow-up times, to improve our understanding of the spinal-pelvic reconstructions used in these patients.

AUTHORS' CONTRIBUTIONS: TPFA (0000-0002-8670-1793)^, AFC (0000-0002-7797-5274) * and TEPBF (0000-0002-0819-7712)* designed the study, interpreted the data and participated in writing the manuscript. DKN (0000-0001-7895-4830) ${ }^{*}$, WGJT (0000-0001-9036-629X)* and FB (XXX) participated in data collection and interpretation and writing of the manuscript. All authors revised and approved the final version submitted for publication, and are responsible for the content of the manuscript. *ORCID (Open Researcher and Contributor ID).

\section{REFERENCES}

1. Feldenzer JA, McGauley JL, McGillicuddy JE. Sacral and presacral tumors: problems in diagnosis and management. Neurosurgery. 1989;25(6):884-91.

2. Nakai S, Yoshizawa H, Kobayashi S, Maeda K, Okumura Y. Anorectal and bladder function after sacrifice of the sacral nerves. Spine (Phila Pa 1976). 2000;25(17):2234-9.

3. Fourney DR, Rhines LD, Hentschel SJ, Skibber JM, Wolinsky JP, Weber KL, et al. En bloc resection of primary sacral tumors: classification of surgical approaches and outcome. J Neurosurg Spine. 2005;3(2):111-22.

4. Hsieh P, Gokaslan ZL. Evaluation and management of spinal axis tumors: benign and primary malignant. In: Winn R, editor. Youmans Neurological Surgery. Philadelphia: Saunders; 2011. p. 3144-53.

5. Doita M, Harada T, Iguchi T, Sumi M, Sha H, Yoshiya S, et al. Total sacrectomy and reconstruction for sacral tumors. Spine (Phila Pa 1976). 2003;28(15):E296-301.

6. Gokaslan ZL, Romsdahl MM, Kroll SS, Walsh GL, Gillis TA, Wildrick DM, et al Total sacrectomy and Galveston L-rod reconstruction for malignant neoplasms. Technical note. J Neurosurg. 1997;87(5):781-7.

7. Newman CB, Keshavarzi S, Aryan HE. En bloc sacrectomy and reconstruction: technique modification for pelvic fixation. Surg Neurol. 2009;72(6):752-6.

8. Shen FH, Harper M, Foster WC, Marks I, Arlet V. A novel "four-rod technique" for lumbo-pelvic reconstruction: theory and technical considerations. Spine (Phila PA 1976). 2006;31(12):1395-401.

9. Guo Y, Yadav R. Improving function after total sacrectomy by using a lumbar-sacral corset. Am J Phys Med Rehabil. 2002;81(1):72-6.

10. Zhang HY, Thongtrangan I, Balabhadra RS, Murovic JA, Kim DH. Surgical techniques for total sacrectomy and spinopelvic reconstruction. Neurosurg Focus. 2003;15(2):E5.

11. Kawahara N, Murakami H, Yoshida A, Sakamoto J, Oda J, Tomita K. Reconstruction after total sacrectomy using a new instrumentation technique: a biomechanical comparison. Spine (Phila Pa 1976). 2003;28(14):1567-72.
12. Mindea SA, Chinthakunta S, Moldavsky M, Gudipally M, Khalil S. Biomechanical comparison of spinopelvic reconstruction techniques in the setting of total sacrectomy. Spine (Phila Pa 1976). 2012;37(26):E1622-7.

13. Zhu R, Cheng LM, Yu Y, Zander T, Chen B, Rohlmann A. Comparison of four reconstruction methods after total sacrectomy: a finite element study. Clin Biomech (Bristol, Avon). 2012;27(8):771-6.

14. Gunterberg B, Romanus B, Stener B. Pelvic strength after major amputation of the sacrum: An experimental study. Acta Orthop Scand. 1976;47(6):635-42.

15. Shen FH, Crowl A, Shuler TE, Feldenzer JA, Leivy SW. Delayed recognition of lumbosacral fracture dislocations in the multitrauma patient: the triad of transverse process fractures, unilateral renal contusion and lumbosacral fracture dislocation. J Trauma. 2004;56(3):700-5.

16. Wuisman $P$, Lieshout $O$, Sugihara S, van Dijk M. Total sacrectomy and reconstruction: oncologic and functional outcome. Clin Orthop Relat Res. 2000;(381):192-203.

17. Kelly BP, Shen FH, Schwab JS, Arlet V, Diangelo DJ. Biomechanical testing of a novel four-rod technique for lumbo-pelvic reconstruction. Spine (Phila Pa 1976). 2008;33(13):E400-6.

18. Yu BS, Zhuang XM, Li ZM, Zheng ZM, Zhou ZY, Zou XN, et al. Biomechanical effects of the extent of sacrectomy on the stability of lumbo-iliac reconstruction using iliac screw techniques: what level of sacrectomy requires the bilateral dual iliac screw technique? Clin Biomech (Bristol, Avon). 2010;25(9):867-72.

19. Yu BS, Zhuang XM, Zheng ZM, Li ZM, Wang TP, Lu WW. Biomechanical advantages of dual over single iliac screws in lumbo-iliac fixation construct. Eur Spine J. 2010;19(7):1121-8.

20. Rahn BA, Gallinaro P, Baltensperger A, Perren SM. Primary bone healing. An experimental study in the rabbit. J Bone Joint Surg Am. 1971;53(4):783-6. 